\title{
A Brief History of Piano Action Mechanisms*
}

\section{Matteo Russo, Jose A. Robles-Linares}

Faculty of Engineering, University of Nottingham, Nottingham, UK

Email: matteo.russo@nottingham.ac.uk, jose.robleslinaresalvelais@nottingham.ac.uk

How to cite this paper: Russo, M., \& Robles-Linares, J. A. (2020). A Brief History of Piano Action Mechanisms. Advances in Historical Studies, 9, 312-329.

https://doi.org/10.4236/ahs.2020.95024

Received: October 30, 2020

Accepted: December 5, 2020

Published: December 8, 2020

Copyright (c) 2020 by author(s) and Scientific Research Publishing Inc. This work is licensed under the Creative Commons Attribution International License (CC BY 4.0).

http://creativecommons.org/licenses/by/4.0/

\begin{abstract}
The action mechanism of keyboard musical instruments with strings, such as pianos, transforms the motion of a depressed key into hammer swing or jack lift, which generates sound by striking the string of the instrument. The mechanical design of the key action influences many characteristics of the musical instrument, such as keyboard responsiveness, heaviness, or lightness, which are critical playability parameters that can "make or break" an instrument for a pianist. Furthermore, the color of the sound, as well as its volume, given by the shape and amplitude of the sound wave respectively, are both influenced by the key action. The importance of these mechanisms is highlighted by centuries of studies and efforts to improve them, from the simple rigid lever mechanism of $14^{\text {th }}$-century clavichords to the modern key action that can be found in concert grand pianos, with dozens of bodies and compliant elements. This paper presents a brief history of this evolution with a focus of mechanism design and development, with an analysis of the most important designs from a technical perspective. Four milestones can be identified in the history of the key action mechanism: the clavichord, the harpsichord, the fortepiano, and the modern piano (including both the grand and upright pianos). In addition, modern electro-mechanical, analogue, and digital instruments are briefly introduced to identify the current trends and discuss possible future developments of key actions.
\end{abstract}

\section{Keywords}

History of Mechanism and Machine Science, Piano, Key Action, Keyboard Musical Instruments

${ }^{*}$ A preliminary version of this work was presented at the $3^{\text {rd }}$ International Conference of IFToMM Italy (IFIT 2020), held in Naples, Italy, on 9-11 September 2020, with proceedings published in the book: Niola V., Gasparetto A. (Eds.). Advances in Italian Mechanism Science. Proceedings of the 3rd International Conference of IFToMM Italy. Mechanism and Machine Science 91, Springer Nature: Switzerland, 2021 (Russo \& Roble-Linares, 2021). 


\section{Introduction}

String keyboard instruments generate sound when a key is depressed by plucking or striking a string through a key action mechanism. The material, thickness, length, and tension of the string determine the pitch of the note that is generated, and a hollow resonating chamber, a soundboard, or an electric circuit amplify the sound, increasing its volume.

Keyboard musical instruments date back to Greek hydraulic organs, ca. $3^{\text {rd }}$ Century BC (Maclean, 1905), which generated sound by forcing pressurized air through pipes of variable length and shape. The organ action mechanism is extremely simple, with each key and pedal behaving as a lever that controls an on/off switch for the corresponding pipe(s). The application of key action mechanisms to string instruments began only in the Late Middle Ages, i.e. $14^{\text {th }}$ and $15^{\text {th }}$ Centuries, (Bie, 1899; Dolge, 1972; Isacoff, 2011), when struck-string clavichord (Brauchli, 1998) and plucked-string harpsichord (Bond, 2003; Kroll, 2019) were invented. Because of its low volume, the clavichord was commonly played as a practice instrument, whereas the harpsichord flourished during the Renaissance and Baroque eras, thanks to composers such as Georg Friedrich Händel (1685-1759) and Johann Sebastian Bach (1685-1750). An extremely wide range of clavichord and harpsichord variants were developed in those years: the pedal clavichord introduced a pedal to practice compositions for organs; the spinet was a harpsichord variant with two strings per key and a bentside design with angled strings to reduce the size of the instrument; the virginal was a small, portable harpsichord with a rectangular design; the two-manual harpsichords introduced a second keyboard and a second set of strings for improved volume dynamics and a wider range of sounds. However, all these instruments shared the same action of their "parents", with the key acting as a lever to lift a hammer in a clavichord, or a jack with a small wedge-shaped end-effector (plectrum) which plucks the string in a harpsichord (Bond, 2003).

The year 1700 was a pivotal moment for key action mechanisms: while working for the House of Medici, harpsichord maker Bartolomeo Cristofori (1655-1731) invented the fortepiano (Badura-Skoda, 2017). This struck-string piano showed significant mechanical improvements from both clavichord and harpsichord, taking the best characteristics of both instruments and merging them in a totally new design: multiple levers were added to amplify key motion; the hammer was guided only halfway to the string, travelling the remaining distance with momentum and thus enabling dynamics such as forte and piano; and a side linkage was included for controlled damping (Isacoff, 2011). Despite the added manufacturing complexity, the rich sound and dynamics of the fortepiano immediately appealed to composers such as Joseph Haydn (1732-1809), Wolfgang Amadeus Mozart (1756-1791), and Ludwig Van Beethoven (1770-1827), who contributed to the success of the piano until the harpsichord all but disappeared (Dolge, 1972). There was no further breakthrough in key action design after the invention of the fortepiano. However, Cristofori's mechanism was slowly upgraded and de- 
veloped into the modern grand and upright pianos, which kept the main concepts of Cristofori's original design but were modified through the centuries to improve robustness, responsiveness, and performance in rapidly repeated notes (Askenfelt \& Jansson, 1982; Reblitz, 1993; Rowland \& Cross, 1998). The development of piano actions peaked at the end of the $19^{\text {th }}$ century, whereas in the $20^{\text {th }}$ century the mechanism designs have stagnated due to several factors, which include-but are not limited to-a conservative approach of musical instrument makers and classically-trained musicians, as well as the rise of electro-mechanical, analogue, and digital instruments.

Electro-mechanical keyboard instruments, which forego soundboards for electric amplification (Roads, 1996; Parakilas, 2002), were invented in the 1920s, but were brought to mainstream fame only after the late 1950s, with pioneering records from Duke Ellington and Ray Charles first, and by rock bands such as The Doors (e.g. in the introduction of Riders on the Storm, 1970) later. Some of these electric pianos used grand/upright mechanisms with hammered strings, e.g. Yamaha CP70, while others replaced strings with metal reeds, e.g. Wurlitzer, or tines, e.g. Fender Rhodes (Shear \& Wright, 2011). A different key action was used for the clavinet (1970s), an electro-mechanical keyboard inspired by the clavichord, widely used by Stevie Wonder (e.g. in the iconic riff of Superstition, 1972) and Billy Preston among others (Remaggi et al., 2012).

In the 1980s, the rise of synthesizers (Vail, 2014), which generate sounds through the analogue or digital synthesis of soundwaves and filters, led to the development of a new action with light spring-loaded keys (synth action). Hybrid design with both springs and weights, called semi-weighted actions, were also developed for improved responsiveness (FATAR Website, 2020). Differently from electromechanical instruments, synthesizers were an immediate success, revolutionizing pop (e.g. Michael Jackson: Thriller, 1982, and A-ha: Take on Me, 1984) and rock music (e.g. Van Halen: Jump, 1983, and Europe: The Final Countdown, 1986), and leading to the creation of electronic music thanks to pioneers like Kraftwerk.

In this manuscript, the evolution of key action mechanisms over the past six centuries is analyzed. In Section 2, the three main families of historical keyboard instruments, namely clavichord, harpsichord, and fortepiano, are described with the main elements and functioning of their key action. Their evolution and influence on current designs are reviewed. In Section 3, modern grand and upright actions are presented with technical details and kinematic schemes. In Section 4 , the impact of electro-mechanical instruments and synthesizers on the evolution of key action mechanisms is discussed, in order to reveal the current design trends and foresee possible future developments.

\section{Evolution of Piano Mechanics}

\subsection{Clavichord}

The clavichord is the simplest string keyboard instrument, developed in the $14^{\text {th }}$ 
century and widely manufactured until the $16^{\text {th }}$ century. It enjoyed widespread success thanks to its reduced shape factor and portability, as shown in the examples in Figure 1. The clavichord action is a simple key lever with a hammer on one end, as in Figure 2(a). This mechanism, described in Table 1, is characterized by greater expressivity than most other keyboard instruments, by enabling volume dynamics, vibrato and control over sound attack and duration. This action, however, leaves limited space for a soundboard, and the extremely low volume of this instrument, together with always-on passive string damping, relegated it mostly to private use, while the harpsichord enjoyed its fame as a concert instrument.

\subsection{Harpsichord}

The harpsichord family includes several musical instruments, from the smaller spinet (Figure 3(a)) and virginal (Figure 3(b)) to the majestic double-manual harpsichords (Figure 3(c)), all sharing the same key action mechanism. The

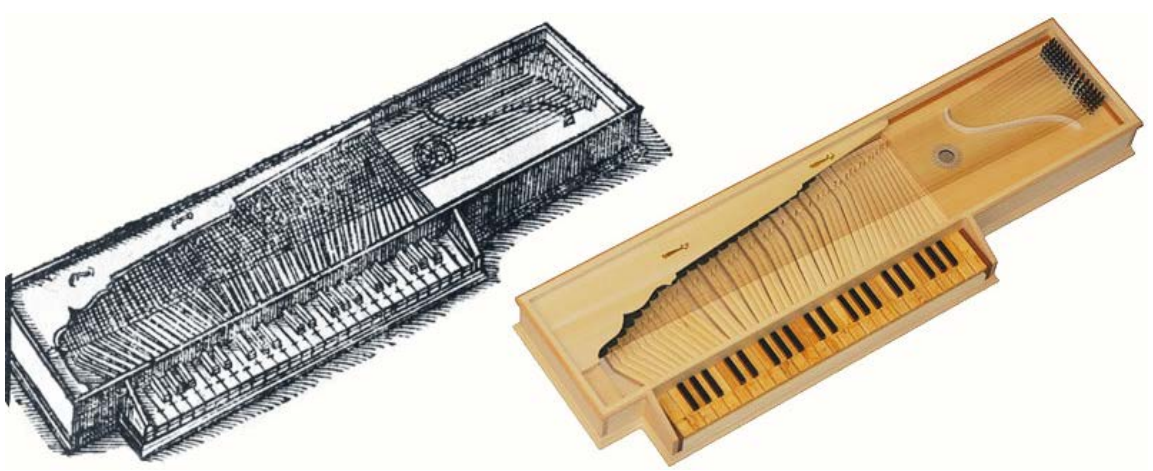

(a)

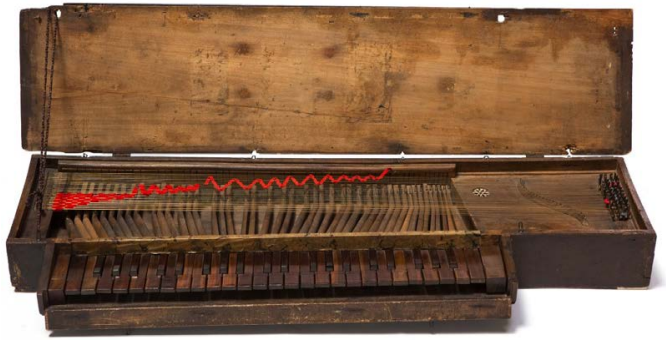

(b)

Figure 1. Examples of clavichord: (a) Modern recreation of a fretted clavichord after Michael Praetorius (1619) (Matthias Griewisch Website, 2020); (b) Clavichord by an unknown maker (ca. 1620) (St Cecilia's Hall Musical Instrument Collection, 2020).

Table 1. Clavichord key action.

\begin{tabular}{cc}
\hline Step & Action \\
\hline 1 & The key is depressed, immediately lifting the hammer on the other side of the lever. \\
2 & The hammer hits the string and remains in contact with it. \\
3 & When the key is released, the hammer goes down. \\
\hline
\end{tabular}




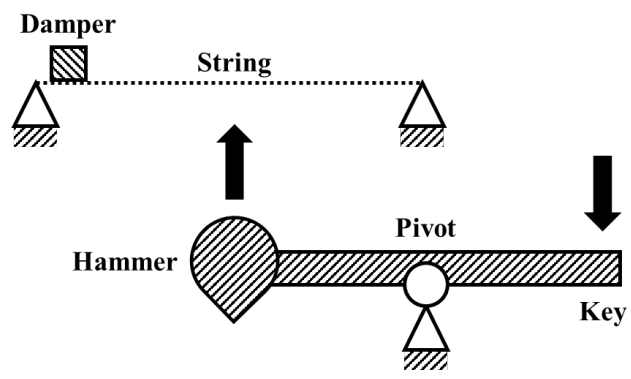

(a)

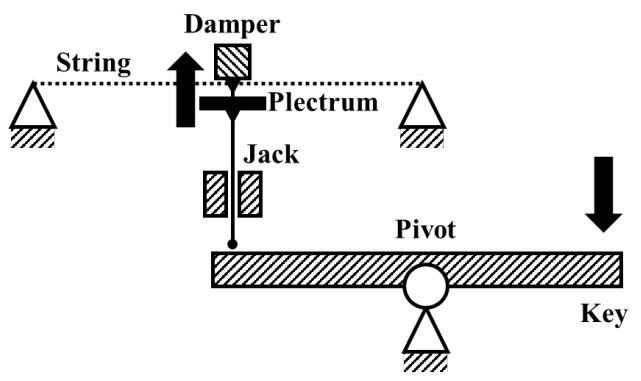

(b)

Figure 2. Simplified kinematic schemes of historical key actions: (a) Clavichord; (b) Harpsichord.

harpsichord action is based on the single lever transmission that is illustrated in Figure 2(b). When depressed, the key lifts a jack that plucks one or more strings with its plectrum and also contains a damper that lets the string resonate, as explained in Table 2. However, the expressivity of the harpsichord is limited when compared to the clavichord: there is almost no volume dynamics, and vibrato cannot be performed. However, the on/off string damping and higher volume (due to multiple strings and larger soundboards) made the harpsichord more successful than the clavichord until pianos replaced them both. Furthermore, instrument makers tried to overcome the limited volume dynamics by adding an additional manual (i.e. an additional keyboard action on top of the main one, as shown in Figure 3(c)), with each key of the upper manual being activated by depressing it or the corresponding lower manual key: in this way, the higher manual plucks a single set of strings with a lower volume, while the lower manual achieves a higher volume by plucking two or more strings with each key.

\subsection{Fortepiano}

The greatest Italian contribution to key action mechanisms is Bartolomeo Cristofori's invention of the fortepiano. Born in Padua in 1655, Cristofori was hired by Ferdinando de Medici, Grand Prince of Tuscany, in 1688, in order to service the court's instruments. Why Prince Ferdinando decided to select an outsider (Padua was part of the Republic of Venice) rather than one of the many harpsichord makers in Florence is still not clear, and a very limited reports on Bartolomeo Cristofori's life are preserved, mostly limited to some notes in the Giornale de' letteratid Italia that Francesco Scipione, Marchese di Maffei (generally 
Table 2. Harpsichord key action.

Step
1 Action
$\begin{aligned} & \text { When the key is depressed, the jack is lifted vertically in its rail, with both } \\ & \text { plectrum and damper. The damper immediately releases the string. }\end{aligned}$
The plectrum hits the string, generating sound.
The jack then meets an upper rail that stops its motion. While the key
is fully pressed, the string is free to resonate.
$4 \quad$ When the key is released, gravity pulls the jack down through a side rail to prevent
the plectrum from hitting the string again. The string is damped again.

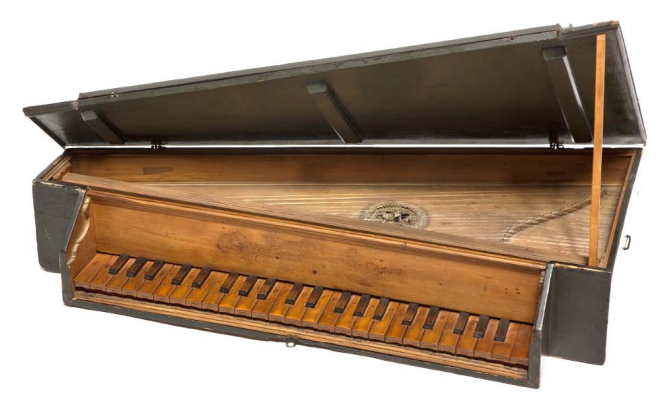

(a)

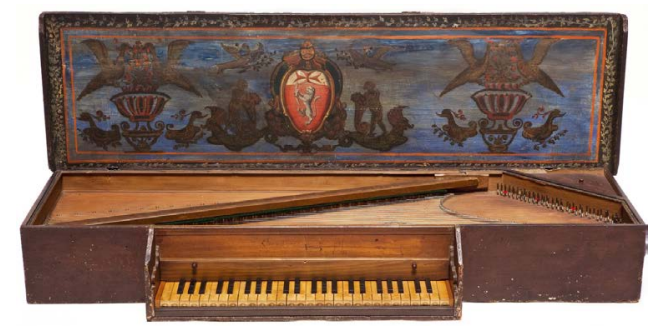

(b)

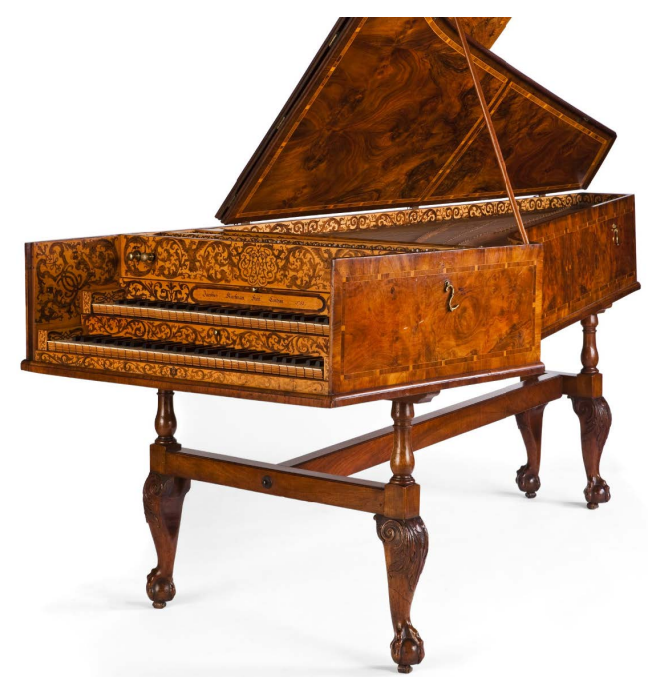

(c)

Figure 3. Examples of harpsichord (St Cecilia's Hall Musical Instrument Collection, 2020): (a) Octave spinet by Petrus Michael Orlandus (1710); (b) Virginal by Francesco Poggio (ca. 1620); (c) Double-manual harpsichord by Jacob Kirkman (1755). 
known as Scipione Maffei), wrote in occasion of his visit to Florence in 1709 (Montanari, 1991). Some researchers (Pollens, 2017) explain this choice with Cristofori's growing fame as instrument maker as well as his possible work on the fortepiano prior to moving to Florence. Prince Ferdinando was an accomplished musician, as well as an enthusiast of horology and other complex mechanical devices, and these factors might have led him to support Cristofori's research.

In Florence, Bartolomeo Cristofori worked in his workshop in the Uffizi's Galleria deiLavori (Pollens, 2017), where he built different kinds of keyboard instruments. An inventory of Prince Ferdinando's musical instruments in 1700 lists seven keyboard instruments by Cristofori: two spinets, a spinettone, three harpsichords (one upright) and "un Arpicimbalo di Bartolomeo Cristofori, di nuovainventione, che fa il piano e il forte, a due registriprincipaliunisoni" (an Arpicimbalo newly invented by Bartolomeo Cristofori, which plays piano and forte, with two main unison stops), which was probably the first fortepiano that he made (Montanari, 1991). Cristofori was a prolific instrument maker, and he kept improving his design until his death in 1731.

Cristofori's original design, often called fortepiano, introduces sweeping changes by introducing additional levers to improve motion transmission, by guiding the hammer only partially to the string and by implementing a damping mechanism as illustrated in Figure 4 and explained in Table 3. With a shape factor similar to the concert harpsichord's one, the fortepiano is characterized by a large soundboard, as shown in the example in Figure 5, resulting in a good volume and a full sound rich in harmonics. The improved control over the damper and the momentum-driven hammer enable expressivity with both volume and tone dynamics.

Table 3. Fortepiano key action.

Action
When the key is depressed, it lifts an intermediate lever. The damper,
connected to the intermediate lever, releases the string.
1 After a small free run, the jack of the intermediate
lever pushes the hammer up.
The hammer separates from the jack halfway to the string and
proceeds to hit the string because of its momentum.
If the key is immediately released, the string is damped again, generating a
staccato sound, and then the mechanism goes back to its resting position.
If the key is pressed down, the undamped string is free to resonate, generating a
longer sound. The hammer then goes back down to the top of the jack.
wh




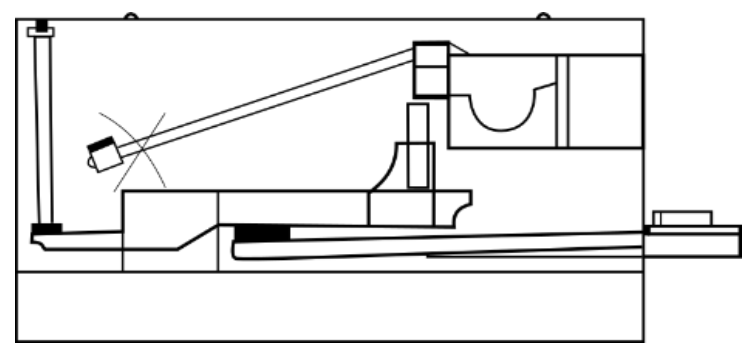

(a)

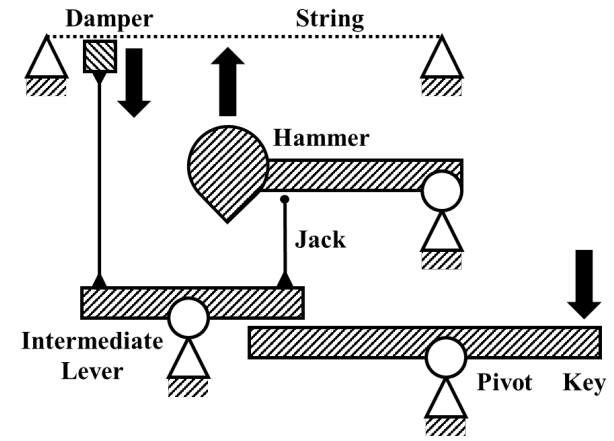

(b)

Figure 4. Fortepiano key action: (a) Cross-section view from an $18^{\text {th }}$-century drawing (Isacoff, 2011); (b) A simplified kinematic scheme.

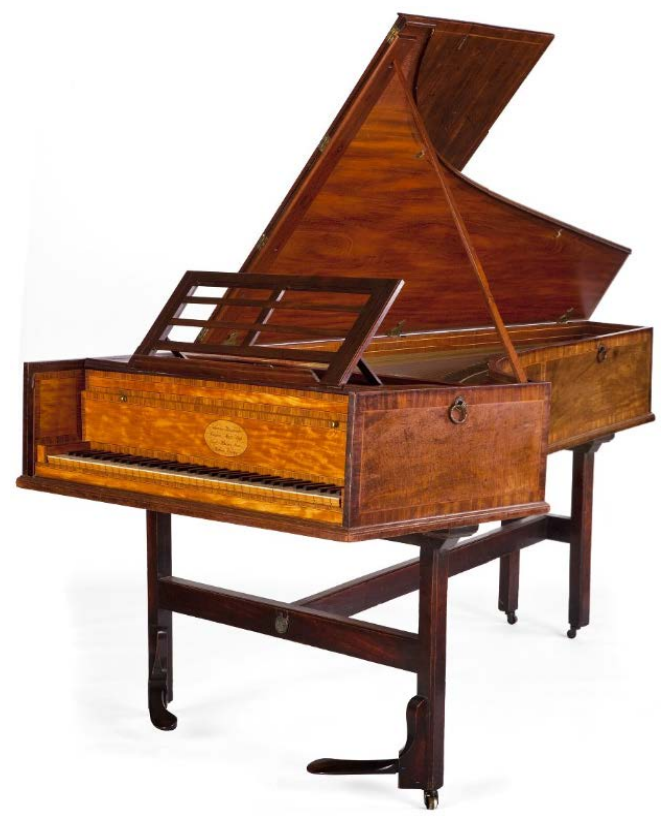

Figure 5. Fortepiano by John Broadwood and Sons (1793) (St Cecilia's Hall Musical Instrument Collection, 2020).

After Cristofori's death, the fame of German and Austrian makers quickly eclipsed the Italian inventor's success. Gottfried Silbermann was aGerman instrument maker who improved Cristofori's design by adding a hand-operated damper lever and introduced the new design to many influential composers of the 
age, including Johann Sebastian Bach (Pollens, 1995). In the $18^{\text {th }}$ century, Johann Andreas Stein developed the Viennese (or German) hammer action, with an alternative hammer arrangement that improved the player's control of the hammers and a damper pedal (Pollens, 1995). Stein's pianos were played by Mozart and Beethoven, among others.

The introduction of a pedal that lifts all dampers independently from the keyboard mechanism also lets all the strings resonate while keys are released. These mechanical changes enabled the shift from early classical piano music, with strong Baroque influences, to romantic music, with composers like Chopin and Liszt integrating the novelties of the fortepiano in their own pieces.

\section{Modern Piano Mechanics}

Cristofori's design was an immediate success, and its usage was boosted by the significant contributions of great composers such as Mozart and Beethoven during the late $18^{\text {th }}$ and early $19^{\text {th }}$ centuries. This, together with the novel production and manufacturing capabilities of the Industrial Revolution (1760-1840), fueled a demand for improved pianos with richer sound and increased stability, robustness, and sensitivity. Thus, the key action of the fortepiano gradually evolved over the course of the $18^{\text {th }}$ and $19^{\text {th }}$ centuries into the consolidated design of the early $20^{\text {th }}$ century, currently used by modern pianos. The modern key action mechanism maintains the main functioning principle of the fortepiano but is characterized by changes that improve sound quality and overall performance. Modern pianos can be upright pianos, with a compact frame that suits domestic use or practice rooms; or grand pianos, with a larger soundboard that fits performance venues and concert halls due to their brighter and richer sound, and with an additional mechanism that enables rapidly repeated notes to favor the pianists' execution.

\subsection{Grand Piano}

The grand piano, shown in the example in Figure 6, is the state-of-the-art instrument for piano concerts. As previously indicated in Figure 4(b), the intermediate lever of a fortepiano was attached to both damper and jack. On the contrary, the grand piano action, in Figure 7, has an independent damping mechanism where the damper is lifted only halfway through the hammer run when the key is depressed. This action, detailed in Table 4 and in the scheme in Figure 8 , is also characterized by a repetition lever that allows to repeat a note even if the key is not fully released. This lever made a breakthrough in piano history by enabling fast note repetition for both soft (piano) or heavy (forte) notes.

Grand pianos have three different pedal mechanisms that are independent from the key action and alter the sound by either providing a lower volume, releasing the dampers from all the strings, or operating the sostenuto mechanism. Pedal mechanisms are held below the keybed of the piano by the pedal lyre, which has structural components that are strong enough to withstand the large 


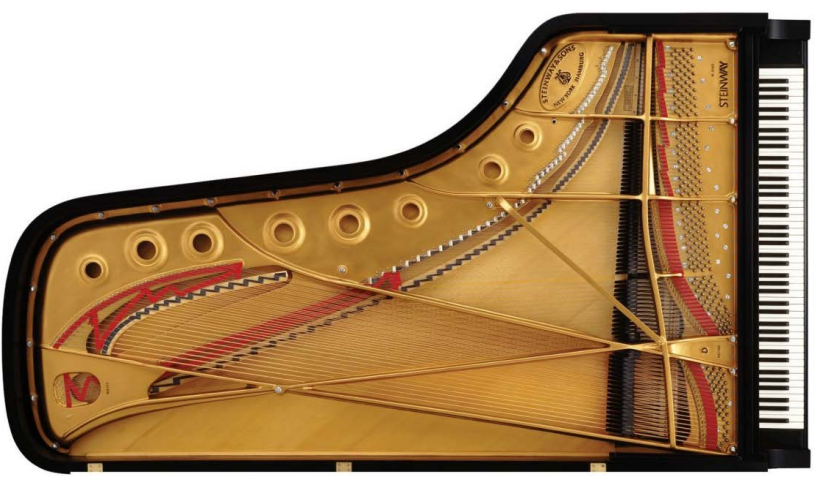

(a)

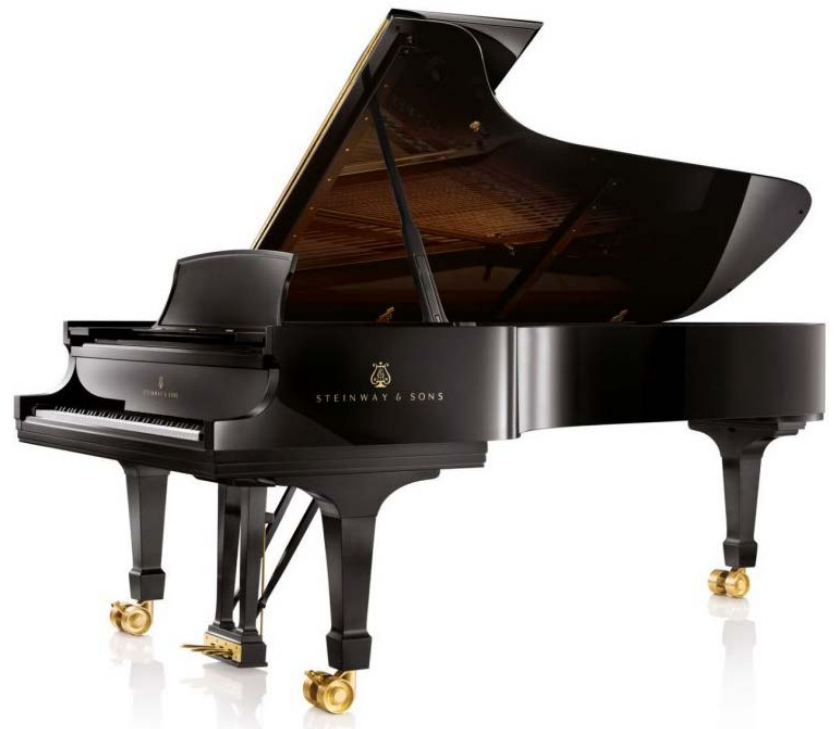

(b)

Figure 6. Model D Concert Grand Piano by Steinway \& Sons (Steinway Website, 2020): (a) A top view with open soundboard; (b) A side view.

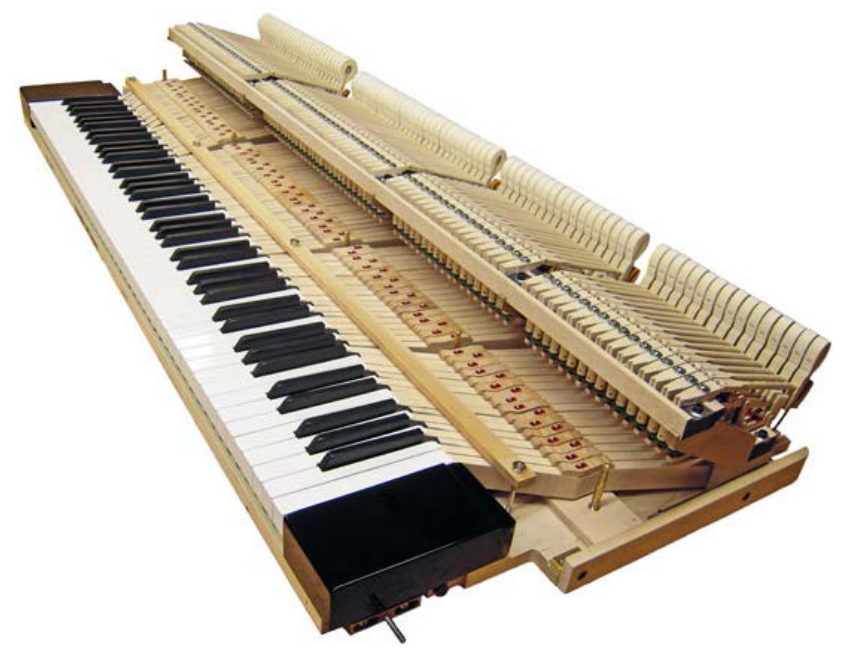

Figure 7. Grand piano action by Donison-Steinbuhler Standard (Steinbuhler Website, 2020). 
Table 4. Grand piano key action.

\begin{tabular}{|c|c|}
\hline Step & Action \\
\hline 1 & $\begin{array}{l}\text { The key is depressed, immediately lifting the wippen and the jack. The latter } \\
\text { pushes on the knuckle and the hammer starts moving upwards. }\end{array}$ \\
\hline 2 & $\begin{array}{l}\text { When the hammer is halfway to the string, the extremity of the key lever } \\
\text { starts pushing the damper upwards, releasing the string. }\end{array}$ \\
\hline 3 & $\begin{array}{l}\text { Slightly before the hammer hits the strings, the jack reaches its motion } \\
\text { limit when its toe is constrained by the letoff button. }\end{array}$ \\
\hline 4 & $\begin{array}{l}\text { The hammer continues moving upwards only by inertia, } \\
\text { until it hits the string and rebounds back. }\end{array}$ \\
\hline 5 & $\begin{array}{l}\text { During the rebound motion, the hammer goes downward, but the knuckle lands } \\
\text { on the repetition lever instead of the jack, kept down by the letoff button. }\end{array}$ \\
\hline 6 & $\begin{array}{l}\text { The hammer's downward inertia pushes the repetition lever down, } \\
\text { and the hammer tail is caught and held in place by the backcheck. }\end{array}$ \\
\hline 7 & If the key is still depressed, the string is free to resonate. \\
\hline $8 \mathrm{a}$ & $\begin{array}{l}\text { If the key is slightly (not fully) released, the backcheck releases the hammer } \\
\text { tail and the repetition lever moves the jack back under the knuckle, }\end{array}$ \\
\hline $9 \mathrm{a}$ & $\begin{array}{l}\text { A new full cycle is enabled without the key being fully released. } \\
\text { This part of the mechanism allows fast-repeated notes to be played. }\end{array}$ \\
\hline $8 \mathrm{~b}$ & $\begin{array}{l}\text { If the key is fully released, the hammer falls back into its rest place, the jack } \\
\text { returns to its rest position under the knuckle, and the string is damped. }\end{array}$ \\
\hline
\end{tabular}

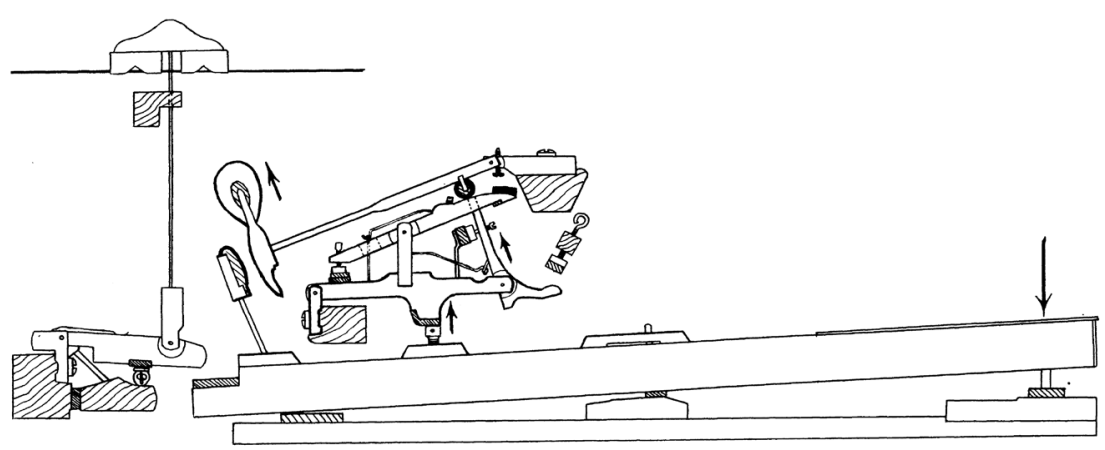

(a)

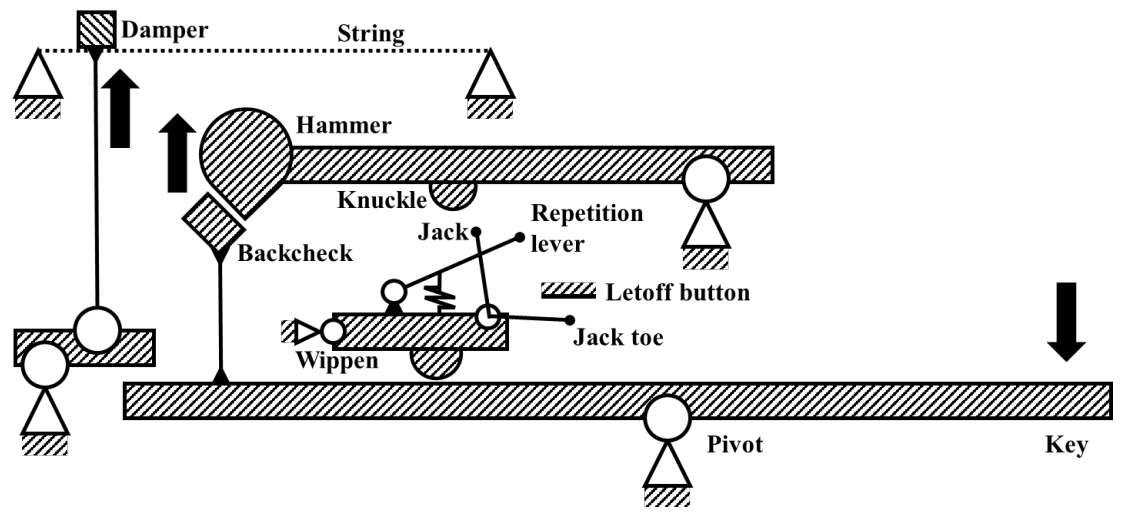

(b)

Figure 8. Grand piano key action: (a) Cross-section view (Reblitz, 1993); (b) A simplified kinematic scheme. 
forces exerted by the pianist's feet (Reblitz, 1993). The left or soft pedal can operate as 1) a shifter, meaning that a lever from the pedal mechanism fits onto a notch in the key frame and moves the whole key action of the piano slightly to the right (i.e. by one string) so that when a key is depressed, only two of its three strings are struck, hence resulting in less sound volume and different tone quality; or 2) a lifter, that brings up the hammer rail slightly closer to the strings, thereby reducing the hammer travel distance and resulting not only in a lower volume, but also in an altered key feel to the pianist that could hinder playability. The right or sustain pedal is an independent mechanism that lifts the damper rail from the key action mechanism, allowing free resonance of all the strings while the pedal is active. Contrary to the sustain pedal, the middle pedal enables the sostenuto mechanism, which essentially sustains only the notes that are depressed at the moment that the pedal is depressed, allowing for any other future notes to be unaffected, independently from the pedal position (Reblitz, 1993).

\subsection{Upright Piano}

The action of an upright piano is designed to fit tight space requirements rather than performance. Therefore, the string layout is vertical rather than horizontal, as illustrated in Figure 9, in order to fit a smaller body frame. The repetition lever of grand pianos is also not included. This design offers the advantage of reduced encumbrance and lower cost. However, its shorter strings and smaller soundboard result in a lower sound quality than grand pianos and the lack of a repetition lever can limit professional pianists in execution. The functioning of an upright piano action is reported in Table 5, and a mechanical scheme is shown in Figure 10.

Most upright or vertical pianos have two pedals (i.e. soft pedal and sustain pedal), but higher cost and quality uprights may also have a sostenuto, a bass sustain or a practice pedal in the middle (Reblitz, 1993). The pedal mechanisms are similar to those of grand pianos, adapted to the vertical arrangement of the strings.

Table 5. Upright piano key action.

Step Action
When key is depressed, the wippen rotates, moving the jack upwards while
compressing the jack spring. The hammer starts to move.
2 The wippen's left end actuates the damper lever, lifting the damper off the string.
3 The hammer continues to move by inertia and hits the string.
5 The hammer rebounds until it gets caught by the backcheck.
6 If the key is still depressed, the string is free to resonate.
7
When the key is fully released, the hammer falls back into its rest place,
the jack returns to its rest position and the string is damped.




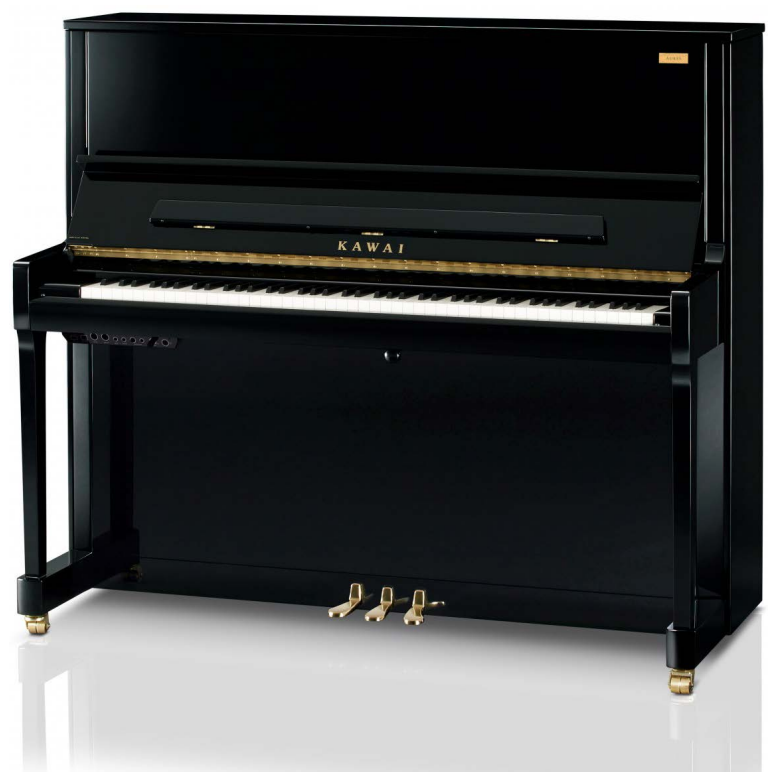

(a)

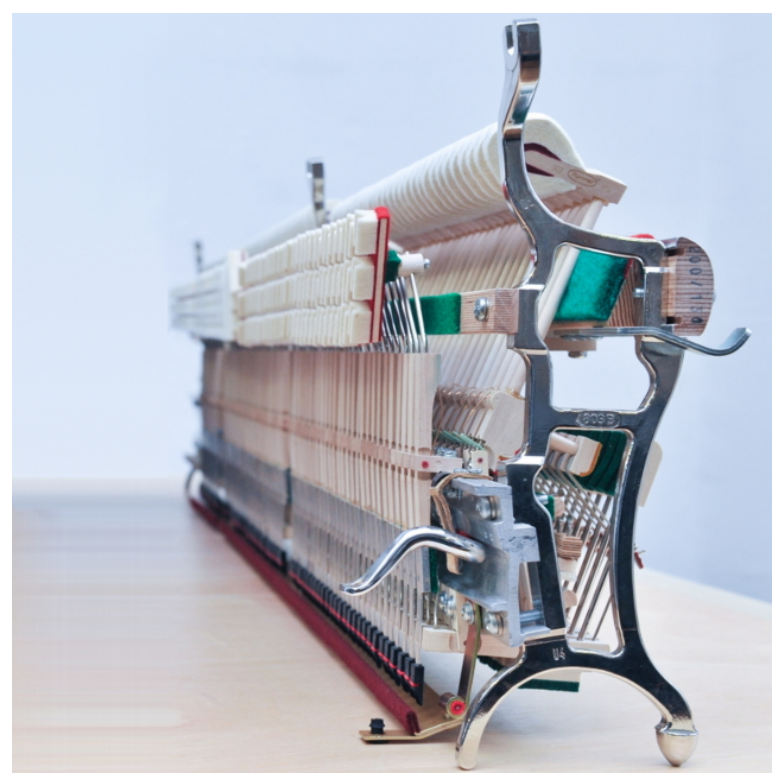

(b)

Figure 9. Examples of upright pianos: (a) Kawai K500 upright piano (Kawai Website, 2020); (b) Steingraeber PS Upright Piano Action (Steingraeber \& Sohne Website, 2020).

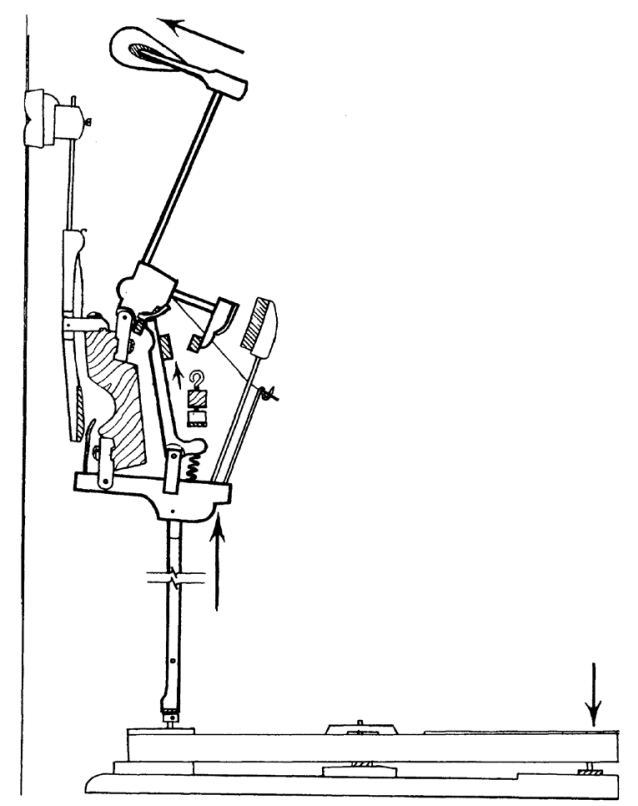

(a)

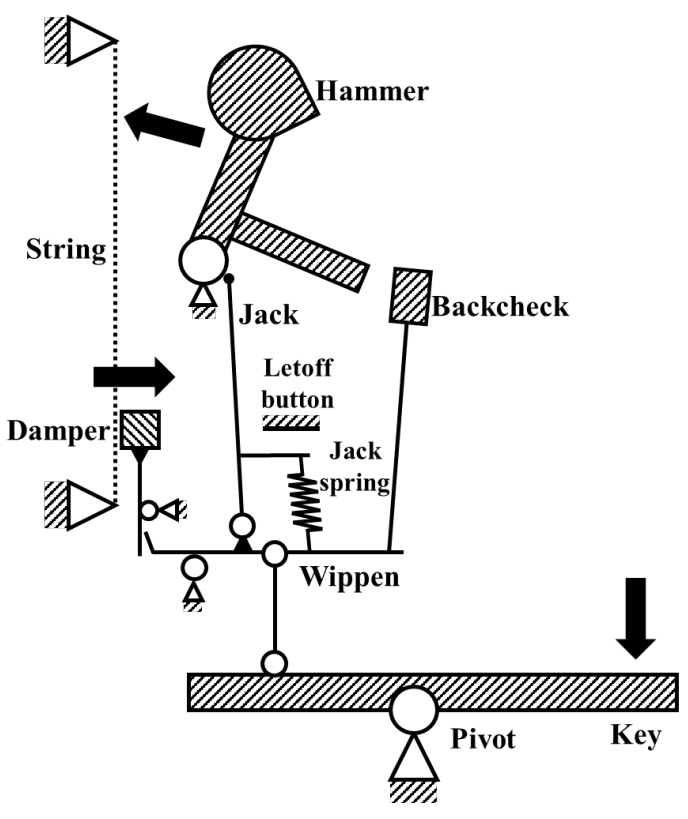

(b)

Figure 10. Upright piano key action: (a) Cross-section view (Reblitz, 1993); (b) A simplified kinematic scheme.

\section{Other Keyboard Instruments}

\subsection{Electro-Mechanical Keyboard Instruments}

The first electro-mechanical keyboards were developed in the late 1920s, and they reached the peak of their success between the 1960s and the 1970s. The main difference between an electro-mechanical and an acoustic instrument can be identified in the soundboard: while acoustic instruments use a resonance 
chamber to amplify the sound and enrich it with harmonics, electro-mechanical instruments acquire the soundwave vibration through a pickup and amplify it electrically. Most electric pianos use fortepiano, grand or upright key action mechanisms, sometimes replacing strings with reeds or tines. For example, the Fender Rhodes piano, shown in Figure 11, uses the key action mechanism shown in Figure 12, which is based on the fortepiano kinematic scheme in Figure 4(b), whereas the clavinet is designed as based on the clavichord mechanism in Figure 2(a). Despite the different functioning and sound of electro-mechanical keyboards, the key action presents no significant change from previous ones.

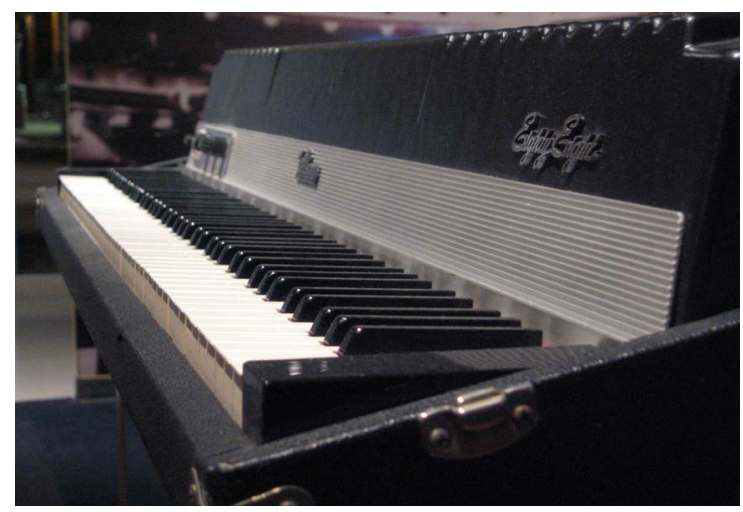

(a)

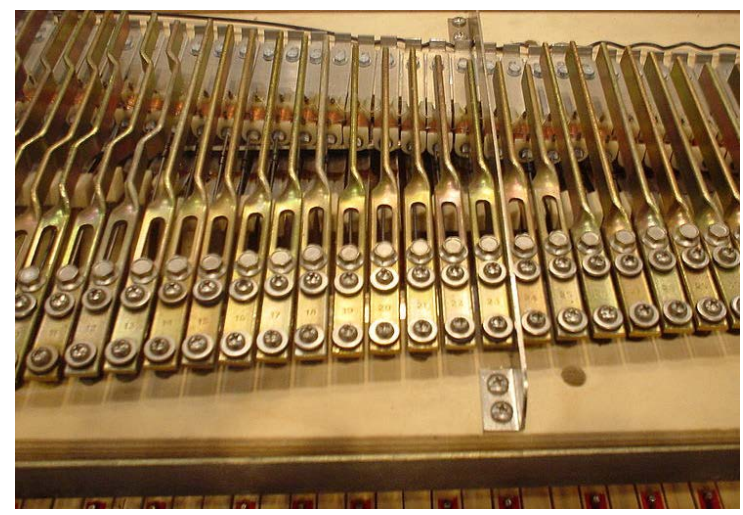

(b)

Figure 11. Fender Rhodes piano: (a) A Suitcase 88 model (1974); (b) A view of the instrument's tines.

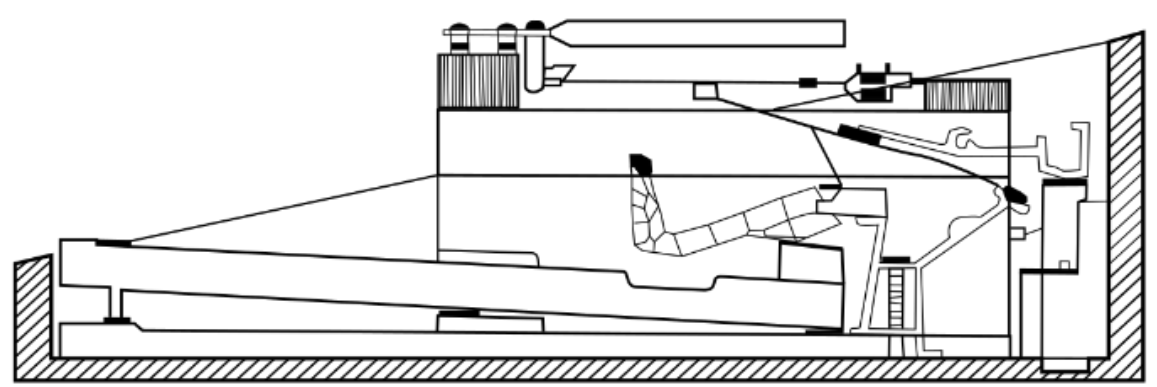

Figure 12. A section view of the Fender Rhodes piano key action mechanism (Rhodes Keyboard Instruments USA, 1979). 


\subsection{Synthesizers}

Modern synthesizers (often shortened as synths), such as the iconic Minimoog in Figure 13, employ a drastically different approach than action mechanisms: instead of generating sounds by striking or plucking strings, reeds, or tines, they depend on electronics for analogue or digital soundwave generation and processing. Thus, synth keys generate numerical values such as ON/OFF signals or velocity signals, which are integers between 1 and 127 under standard MIDI protocol. For this reason, a single lever with an electronic sensor is enough, with a spring (sometimes with added weight) to return the key up after release, as shown in Figure 14. This mechanism, detailed in Table 6, is independent from gravity, enabling vertical keyboard layouts. Furthermore, synth action is extremely affordable, lightweight, and compact. Its mechatronic nature, however, can limit the expressivity of the instrument, even if additional tools are often added to compensate, e.g. pitch bend and modulation levers, aftertouch sensors, low frequency oscillators, ADSR parameters, filter cutoff and resonance knobs (Vail, 2014). For this reason, an additional mechatronic control known as aftertouch is sometimes added to premium synth actions to enable pressure sensitivity. The aftertouch is achieved by adding a pressure sensor beneath the keys to record and transmit MIDI signals related to pressure variations on a depressed key, which can be associated to effects such as vibrato or tonal changes.

Table 6. Synth key action.

\begin{tabular}{|c|c|}
\hline Step & Action \\
\hline 1 & When the key is depressed, it rotates around the pivot point up to its limit \\
\hline 2 & $\begin{array}{l}\text { A velocity sensor measures key velocity and transmits the information } \\
\text { as a MIDI message to the sound generation unit. }\end{array}$ \\
\hline 3 & $\begin{array}{l}\text { While key is pressed down, the sensor keeps sending the MIDI } \\
\text { signal without changing the velocity value. }\end{array}$ \\
\hline 4 & $\begin{array}{l}\text { While keeping the key depressed, a change in pressure on the key } \\
\text { sends an aftertouch MIDI signal if the keyboard allows it. }\end{array}$ \\
\hline 5 & $\begin{array}{l}\text { When the key is released, the signal stops and the spring pushes } \\
\text { the key back to its resting position. }\end{array}$ \\
\hline
\end{tabular}

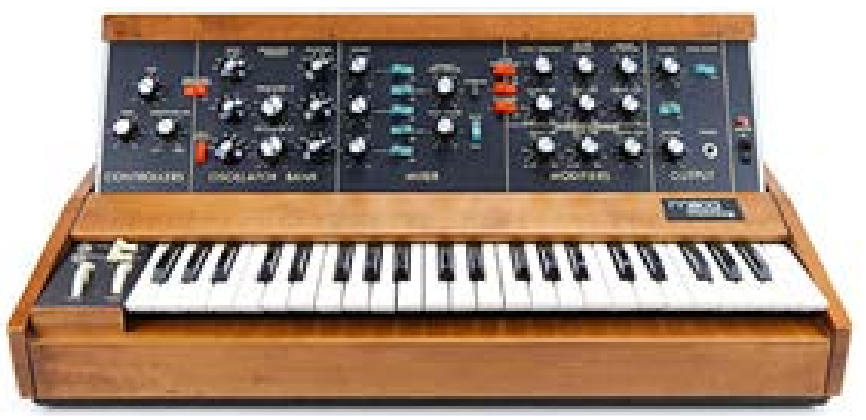

Figure 13. Minimoog by Moog Music (1970). 


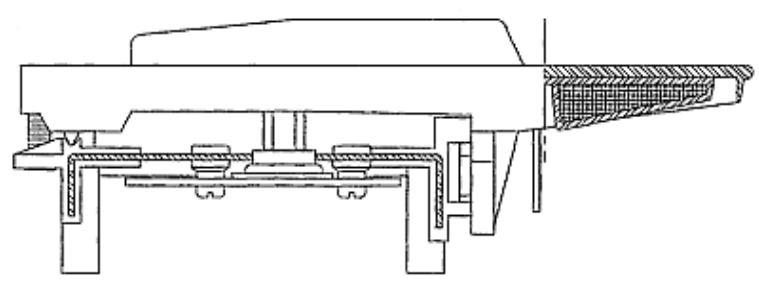

(a)

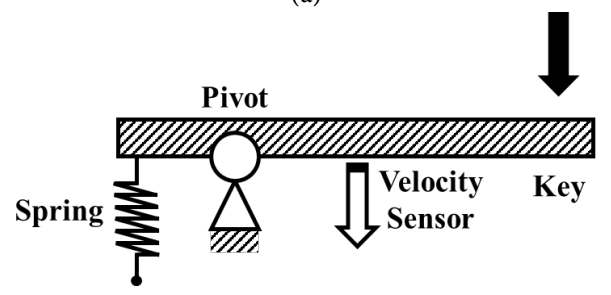

(b)

Figure 14. Synth key action: (a) Cross-section view of FATAR TP 9S keybed, (FATAR Website, 2020); (b) A simplified kinematic scheme.

\section{Conclusion}

In this paper, the evolution of key action mechanisms was described chronologically through seven milestone designs: clavichord, harpsichord, fortepiano, grand piano, upright piano, electro-mechanical piano, and synthesizer. Each of these musical instruments was reviewed with historical context and main technical and musical characteristics. The kinematics and functioning of each key action mechanism were analyzed in detail, and their main advantages and drawbacks were identified from both a technical and artistic standpoint. Overall, piano mechanics breakthroughs resulted from two major factors: technological advancements and demand for sound quality. Between the $14^{\text {th }}$ and the $17^{\text {th }}$ centuries, the evolution of key action mechanisms was ruled by the need for improved volume, leading to the development of the fortepiano. Then, during the $17^{\text {th }}$ and $18^{\text {th }}$ centuries, the Industrial Revolution enabled the production of more complex mechanisms for both the key and pedal actions to favor dynamics and responsiveness, and so grand and upright pianos were born. In the $20^{\text {th }}$ century, acoustic piano mechanisms have stagnated with no significant design changes in key action, while analogue and digital musical instruments fulfilled the rising demand for new sounds as well as the need for cheaper alternatives. Current development trends focus on enhancing the expressivity of music performance through mechatronics and digital tools, rather than by improving the mechanical design of the instrument.

\section{Conflicts of Interest}

The authors declare no conflicts of interest regarding the publication of this paper.

\section{References}

Askenfelt, A. G., \& Jansson, E. V. (1982). Piano Touch, Hammer Action, and String Mo- 
tion. The Journal of the Acoustical Society of America, 71, S92. https://doi.org/10.1121/1.2019638

Badura-Skoda, E. (2017). The Eighteenth-Century Fortepiano Grand and Its Patrons: From Scarlatti to Beethoven. Bloomington, IN: Indiana University Press. https://doi.org/10.2307/j.ctt2005v7j

Bie, O. (1899). A History of the Pianoforte and Pianoforte Players. Darlington: JM Dent.

Bond, A. (2003). A Guide to the Harpsichord. Winona, MN: Hal Leonard Corporation.

Brauchli, B. (1998). The Clavichord. Cambridge: Cambridge University Press.

Dolge, A. (1972). Pianos and Their Makers: A Comprehensive History of the Development of the Piano from the Monochord to the Concert Grand Player Piano (Vol. 1). North Chelmsford, MA: Courier Corporation.

FATAR Website (2020). http://www.fatar.com

Isacoff, S. (2011). A Natural History of the Piano: The Instrument, the Music, the Musicians -From Mozart to Modern Jazz, and Everything in Between. New York: Knopf.

Kawai Website (2020). https://www.kawai.co.uk

Kroll, M. (2019). The Cambridge Companion to the Harpsichord. Cambridge: Cambridge University Press. https://doi.org/10.1017/9781316659359

Maclean, C. (1905). The Principle of the Hydraulic Organ. Sammelbände der Internationalen Musikgesellschaft, 6, 183-236.

Matthias Griewisch Website (2020). http://www.griewisch.com

Montanari, G. (1991). Bartolomeo Cristofori: A List and Historical Survey of His Instruments. Early Music, 19, 383-398. https://doi.org/10.1093/earlyj/XIX.3.383

Parakilas, J. (2002). Piano Roles: A New History of the Piano. London: Yale Nota Bene.

Pollens, S. (1995). The Early Pianoforte. Cambridge: Cambridge University Press.

Pollens, S. (2017). Bartolomeo Cristofori and the Invention of the Piano. Cambridge: Cambridge University Press. https://doi.org/10.1017/9781316156292

Reblitz, A. A. (1993). Piano Servicing, Tuning, \& Rebuilding: For the Professional, the Student, the Hobbyist. Lanham: Vestal Press.

Remaggi, L., Gabrielli, L., de Paiva, R. C. D., Välimäki, V., \& Squartini, S. (2012). A Pickup Model for the Clavinet. Proceedings of the 15th International Conference on Digital Audio Effects (DAFX-12), York, Vol. 1721, DAFX 1-5.

Rhodes Keyboard Instruments U.S.A. (1979). Service Manual.

Roads, C. (1996). Early Electronic Music Instruments: Time Line 1899-1950. Computer Music Journal, 20, 20-23. https://doi.org/10.2307/3680817

Rowland, D., \& Cross, J. (1998). The Cambridge Companion to the Piano. Cambridge: Cambridge University Press. https://doi.org/10.1017/CCOL9780521474702

Russo, M., \& Robles-Linares, J. A. (2021). A Brief History of Piano Mechanics. In Advances in Italian Mechanism Science. Proceedings of the 3rd International Conference of IFToMM Italy (pp. 11-19). Mechanism and Machine Science 91, Berlin: Springer Nature. (In Press) https://doi.org/10.1007/978-3-030-55807-9 2

Shear, G., \& Wright, M. (2011). The Electromagnetically Sustained Rhodes Piano. NIME Proceedings, Oslo.

St Cecilia’s Hall Musical Instrument Collection (2020).

https://collections.ed.ac.uk/stcecilias

Steinbuhler Website (2020). http://www.steinbuhler.com

Steingraeber \& Sohne Website (2020). https://www.steingraeber.de 
Steinway Website (2020). https://www.steinway.com

Vail, M. (2014). The Synthesizer: A Comprehensive Guide to Understanding, Programming, Playing, and Recording the Ultimate Electronic Music Instrument. Oxford: Oxford University Press. 